\title{
Xenophobia and Class Conflicts Among Venezuelan Migrants: An Ethnographic Study in the City of Ibarra, Ecuador
}

Jorge Mantilla

Universidad de Otavalo, Ecuador

\section{ARTICLE INFO}

Keywords:

Transnational Migration

Xenophobia

Violence

Ecuador

\begin{abstract}
In recent years, the city of Ibarra, Ecuador has received nearly 10,000 migrants from Venezuela. In this municipality, the relations between locals and migrants are quite complex. In January 2019, a group of local residents physically assaulted several Venezuelan migrants (Case Diana). These acts had a xenophobic nature. Through ethnographic research, this article analyzes the social dynamics at this city in the months after these events. The research showed that, on the one hand, after these events migrants criticized homogenizing discourses, highlighting the group's own heterogeneity. On the other, migrants also strengthened cooperation networks based on belonging to Venezuelan nationality. The article is aimed to shed light on intergroup dynamics in intermediate cities in the context of the evergrowing Venezuelan migration in Latin America.
\end{abstract}

\section{Introduction}

Ibarra is a city of nearly 131,000 inhabitants, located in northern Ecuador, 73 kilometers from the Colombian border. Given its geographical position, this town has historically received some migratory flows of people from Colombia. In recent years there has also been a massive arrival of people from Venezuela. According to press data, in 2019 about 10,000 Venezuelan migrants lived in Ibarra.

These new migratory movements are not an isolated phenomenon, but rather respond to one of the greatest migratory crises in the recent Latin American history: the massive exodus of Venezuelan citizens to other countries in the region (Leónova, 2019). In the wake of the growing economic, social and political crisis in Venezuela, millions of people have turned to cross-border migration as a survival strategy (Palotti et al. 2020). Although the Venezuela crisis can be traced through time, the difficulties of this country have increased considerably during the government of Nicolás Maduro, due to multiple factors that include failed state policies and the collapse of oil prices (Pantoulas and McCoy, 2019). Elements such as hyperinflation, insecurity, corruption or the poor quality of the health system have pushed living conditions in Venezuela to the limit. Consequently, the number of migrants from this country around the world has increased exponentially. According to UNHCR data, in 2015 approximately 695,000 people migrated from Venezuela; in 2019 the number increased to 4 million.

The Venezuelan migratory flows in the city of Ibarra began around 2015 and have increased considerably ever since. In the first years of this phenomenon, the profile of these migrants was generally associated with people with sufficient economic, social and professional capital. However, since approximately 2017 this profile began to diversify, due to the arrival of a large number of people from multiple regions of Venezuela, including migrants with limited economic resources and professional training.

* Corresponding author E-mail address: jmmantilla@uotavalo.edu.ec 
The reactions of the local population to this phenomenon are complex. At the beginning, the perceptions of local population about migrants were quite positive; However, this changed radically in time, giving way to attitudes close to xenophobia. In January 2019 there was an unexpected turning point: a young Venezuelan migrant murdered his Ecuadorian partner on a street in downtown Ibarra. Although this event had no relation to the nationality of the criminal, this crime provoked a series of actions of xenophobic nature against the Venezuelan population. These events were named as the "Diana Case".

Understanding the dynamics associated with "the Diana Case" is fundamental for anthropology in Latin America, due to the importance of the Venezuelan migration for the region and especially for medium-sized cities like Ibarra. This article presents the results of an ethnographic study carried out in the months after these events, focusing on the responses of the migrant population. Following a theoretical orientation that emphasizes the importance of strategic positionality in the construction of identities (Karam, 2020; Lacy, 2007), the paper emphasizes two points: First, after the Diana Case there was an emergence of discourses whereby migrants seek to underline the heterogeneity of the Venezuelan community. Second, cooperation networks between migrants were maintained even after these events.

\section{Methodology}

This research had mainly an ethnographic approach (Pardo and Prato 2018; Beuving and De Vires 2015). The information was collected as part of a research project developed between January 2019 and January 2020. Data was collected through participant observation and 46 indepth interviews (30 men, and 16 women). We used a snowball sampling to select our informants. Regarding ethnicity, most of the participants identify themselves as white or mestizo people. The information was collected in different parts of the city, not limited to a particular area or neighborhood.

\section{Theoretical Perspectives on Xenophobia and Migratory Identities}

In general terms, xenophobia has been defined in the academic literature as an antipathy or hate towards migrants or foreigners (Hjerm and Nagayoshi, 2011). The naturalization of negative attitudes, exaggerations and the language of hyperbole associated with xenophobia generates situations in which derogatory treatment of migrant populations becomes acceptable, facilitating hate speech, harassment, intimidation, social exclusion, economic exclusion and other forms abuse (Crush and Ramachandran, 2010). In recent times, where cross-border migration has become extremely prevalent, understanding the logics and structures associated with xenophobic discourses and practices is a fundamental task (Kraly and Hovy, 2020).

One of the common features of xenophobic narratives is the generation of a dichotomous worldview that separates local from foreign populations. Within these narratives, both groups are usually presented as homogeneous entities, with fixed characteristics. Therefore, the multiplicity of experiences, identities, and backgrounds of the migrant population is not considered. In this sense, homogenization is a constitutive element of the rationalities of xenophobia (Archakis, 2018).

In the academic literature, there are still theoretical developments that do not consider the diversity of migrant populations. For example, the theory of intergroup contact seeks to establish correlations between the number of migrants and the attitudes of the local population. According to this theory, the higher the proportion of migrants in a locality, the lower the level of xenophobic attitudes (Wagner et al. 2020; Schlueter and Scheepers 2010). Likewise, threat theory studies the interactions between minority and majority groups, noting that the symbolic and real threats of migration can generate forms of intergroup anxiety or negative stereotypes 
among the local population (Landmann, Gaschler, \& Rohmann, 2019; Harrison and Peacock 2010). In both theories, internal characteristics, and diversity of migrant populations is not considered.

For this paper it is fundamental to adopt a theoretical approach that considers the interactions between migrant and local populations, while still considering the internal diversity and complexity of migrant groups. To this end, contemporary studies based on the inter-ethnic borders theory developed by Fredrik Barth (1998) are of great relevance. From this perspective, the construction of identities in migration contexts is developed based on complex negotiation processes in which individuals strategically construct and renegotiate their identities (Karam 2020; Lacy 2007). This strategic development of identities can be generated both at a discursive level, as well as through practices such as the creation of migratory networks (Deker and Engbersen 2014).

\section{Venezuelan Migration in the City of Ibarra, Ecuador}

Of the nearly 300,000 Venezuelan inhabitants in Ecuador, approximately 10,000 are located in Ibarra (IOM, 2020). This city has a very limited economy, focused mainly on construction, internal trade, and textile production (INEC 2010). The arrival of Venezuelan migrants to this town is explained due to its geographical proximity to the border crossings with Colombia. This proximity facilitates the generation of a migration network that allows access to resources and information.

Most of the Venezuelan migrants in Ibarra is dedicated to commerce, both formal and informal. There are also professionals, in the areas of education and public health. In general, the situation for this group is not always straightforward. There are high levels of informal work with very low remuneration. Access to formal work is developed without respecting the minimum regulations regarding basic wages, working hours or other labor rights. Sexual exploitation is also relatively common.

The group of Venezuelan people in Ibarra is mostly young. Their social, economic and cultural backgrounds are quite diverse. This heterogeneity is especially marked in the socioeconomic sphere. At the beginning of this migration movement, most migrants had an economic, social or academic capital that facilitated a successful life within the city; However, over time this profile diversified widely, including people in more precarious conditions. The experiences of these groups are quite different.

Although there are no formal or legally constituted organizations that bring together this population, in practice, various internet platforms become spheres that serve the purpose of bringing together members of this group. In fact, only on Facebook there are 5 public groups aimed at Venezuelan people residing in Ibarra with more than 1,000 users each. As will be seen later, these groups play an important role in generating collaborative networks and a sense of imagined community (Anderson, 2006).

The interrelationships between Venezuelan and local residents are complex. Although Ecuador is a country whose constitution recognizes interculturality as one of its fundamental elements (Rodríguez Cruz, 2018), in practice, the development of intercultural policies has focused mainly on indigenous groups, omitting the diversity generated from migration movements. In this sense, there are few public programs aimed at promoting intercultural relations between the local and foreign population. In Ibarra there are no areas inhabited exclusively by the Venezuelan population, which implies that the housing, labor, commercial, health or educational spheres are shared between locals and foreigners. This is possible by the use of common language (Spanish) among both groups.

Our fieldwork showed that migrants with more years living in Ibarra categorize the reception of the local population during the first years after their arrival as positive, emphasizing feelings 
of empathy and curiosity by local population. In fact, for many their nationality actually facilitated their access to the labor market. With time - and the increase and diversification of migration in the city - these perceptions and attitudes began to change radically. Practices and discourses based on xenophobia began to be more common.

The daily life of the Venezuelan population living in the city of Ibarra was transformed from a series of violent events that occurred in January 2019. Information on this is presented below.

\section{Gender Violence and Xenophobia in Ibarra: "The Diana Case"}

On January 19, 2019, a case of gender violence occurred in Ibarra: a 22-year-old man kidnapped his partner -in a state of pregnancy- and stabbed her in one of the busiest streets in the city. During these events, a crowd gathered around the kidnapper and his hostage, including bystanders, more than 20 police officers, and the media. Several people broadcasted the event live through social networks, so the events had a live coverage of thousands of people. After more than an hour of negotiations, the events ended in the death of the hostage due to a series of stab wounds. Although the motivations of the case are related to domestic and gender violence, the information on the media and social networks emphasized a different element: the kidnapper had Venezuelan nationality, while the hostage was Ecuadorian. In the media, these events became known as "The Diana Case."

In the minutes after this crime, a small group of Ecuadorian residents walked through various streets of the city with the aim of expelling Venezuelan migrants from the area by means of violence. Several members of this mob entered some migrant residences, took their possessions and threw them into the street to light them with fire. Estefanía, a 31-year-old Venezuelan migrant, who witnessed the events remembers them in the following way:

They forced the entrance of the building, but before we had already been following the live streaming of the event, but I saw people outside, because they said that Venezuelans get out of here! Murderers! And those strong accusations worried us, but We did not believe that this would transcend, and during the event we already had them at the gate. We freaked out so we turned off all the lights. As they listened as they came up with sticks and shouting obscenities, I thought of my daughter and thankfully at 9:00 p.m. she was asleep and did not hear anything. There were about 9 people in the building, but the number of people who went upstairs, broke down doors, smashed windows, entered the living room, burned clothes, threw the washing machine out the window, took a tablet, was they brought their working instruments, it was definitely the biggest and most exasperating scare. To think that your life tended by a thread and the male people inside the building would not have been able to cope with them, because they were willing to do anything (Estefanía, Personal Interview, March 2019).

The xenophobic events of that night ended with material, economic and psychological losses. There were no injuries or deaths. In the following days, these events gained notoriety in local and international press, including media such as the New York Times. The events also had an impact on the political field: after a few days, the president of Ecuador, Lenin Moreno, wrote on Twitter in the following terms:

Ecuador is and will be a country of peace. I will not allow any antisocial to take it from us. The integrity of our mothers, daughters and companions is my priority. I have ordered the immediate formation of brigades to control the legal situation of Venezuelan immigrants on the streets, in the workplace and on the border. We analyze the possibility of giving a special permit to enter the country. We have opened doors for you, but we will not sacrifice anyone's safety. It is the duty of the Police to act harshly against delinquency and crime, and they have my support. We will apply the 
full weight of the law to those who did nothing in the face of violence, injustice and the exercise of criminal power.

The president's speech did not focus on the gender-based motivations of the events, but on the migratory situation of the aggressor. The literature has shown that social networks can become spaces for the dissemination of xenophobia (Martínez et al. 2019; Bursztyn et al. 2019). The dissemination of these type of information through media, especially from government officials, can facilitate xenophobic behaviors and narratives (Peterie and Neil, 2020). In this particular case, far from reducing the existing tension, the president's messages on social networks contributed to creating an atmosphere of concern among the Venezuelan community. The daily life of the Venezuelan population was strongly affected during the days after these events. Their routines of work, school or recreation were changed due to fear. In this regard, Eduardo, a migrant of approximately 40 years dedicated to commerce, reflects on the tension that exists in daily life during the weeks after these events:

(...) I just experience a few days of tension eh, it was very noticeable that many people left the city because there was simply much more rejection eh. The Ecuadorian people had already taken to the streets to protest, and there was aggression against Venezuelans who lived in their different homes, the burning of their clothes, their belongings, and all their things. That is, there were moments of tension for many, they did not leave their homes, eh, for the simple fact of fear that they would attack them and all those things (Eduardo, Personal Interview, March 2019).

Although the acts of violence in the Diana Case were perpetrated by a small group, their effects were more general: a tension developed within the city that influenced the Venezuelan community, regardless of whether they had witnessed the acts of violence or not. In the following weeks, when accompanying several informants in their daily activities, changes in daily routines were observed, such as, for example, advancing the time to return home for fear of being alone at night. In other words, new patterns of care were created. For example, Juan a worker at a local electronics store - emphasized the effect of this situation on the children of migrants "after what happened in January for several days they were not taken (the children) to their schools, there are children who have been victims of bullying". It would take several more weeks for these routines to return to normal cycles.

Far from representing an isolated event, the Diana Case was an expression of a growing trend of animosity and prejudice towards the Venezuelan population. The Diana Case created a liminal space that allowed the explicit development of violent attitudes towards migrants. These were not individual acts, but rather a type of collective violence that was intended to be justified as a response or "punishment" to a particular type of crime. Unlike other forms of collective violence documented in Ecuador such as lynchings, this response was not developed directly against the alleged aggressor but against the community to which he belongs, inscribing within the logic of homogenization typical of xenophobia.

These marked a turning point in the relations between social groups in Ibarra. The responses and consequences of these acts have been multiple. In the following, we analyze the narratives on heterogeneity and cooperation networks between migrants.

\section{Strategic Identity: Criticism of Homogenization and Participation in Migrant Networks}

A few months after the events of the "Diana Case" we found ourselves talking with Patricia, a migrant who arrived in Ibarra before 2015 and is dedicated to school teaching. While we were talking about the Diana Case, Patricia focused on rejecting these violent practices; her tone, however, changed as she discussed her opinions about her compatriots in Ibarra. "Here where 
I live used to be a very quiet place, but unfortunately some Venezuelans have made disasters, but not all of us are like that." Later, she continued to reflect on the existing differences within the migrant group, arguing that, if initially the reception by the local population was very good, these perceptions gradually deteriorated due to the arrival of new migrants. In a similar conversation with Lizeth, a 27-year-old Venezuelan migrant employed in the textile sector, expressed herself in these terms: "We are not all the same, we do not all have the same mentality." She then mentioned: "We came here with (...) the desire to move forward and to improve ourselves; and other people because unfortunately their heads are badly damaged, because they arrive and want to have everything easy". The narratives described in this paragraph emphasize the internal class and social divides between migrants. Their narratives criticized the homogenization of migrant populations. From their standpoint, the xenophobic acts in the Diana Case could be explained by the fact that many people associated the characteristics of the murderer with all migrants.

The migration literature has documented similar cases of differentiation processes. An example of this is the Cuban migration of the "Marielitos" in the United States. After the Cuban revolution, a first group of exiles left the island for economic or political reasons, generally being people with high economic or social capital. In 1980, however, a new group of approximately 125,000 migrants known as Marielitos arrived in the United States. This time it was not people of upper or middle social class, but of people "from the third world", with multiple social, economic and even criminal problems. These generated antipathy responses from the first group of Cuban migrants (Borneman 1986).

The articulation between xenophobic practices and discourses against homogenization by Venezuelan migrants can be understood from the processes of negotiation and construction of identity (Karam, 2020; Lacy, 2007; Barth, 1998). From this perspective, identity is not a fixed or static category, but rather a strategic construction subject to symbolic developments that redefine the relationships between members within and outside the group. In the city of Ibarra, this strategic flexibility allows the development of narratives that emphasize the heterogeneity of the group, but at the same time, allow migrants to maintain network connections based on belonging to a nationality.

First, narratives that point to the heterogeneity of the migrant group are quite common. In a strategic way, these discourses criticize homogenization practices that may be related to the existence of xenophobia (Conversi, 2009; Archakis, 2018). Migrants try to break with this homogeneous and static vision of identity. For example, in an interview Eduardo, a 40-yearold businessman, mentioned the following:

We all know that there are good people and bad people and unfortunately that person came with some mental imbalance due to the same situation that exists there in Venezuela, but we also have resilient people, wanting to get ahead, but not all Venezuelans come with the intention of doing harm, and we repudiate that situation that occurred with that Ecuadorian (Eduardo, Personal Interview, March 2019).

The violent events of the Diana Case create a framework in which breaking with homogenizing visions of migration became essential. It is important to note that migrants' narratives emphasize the heterogeneity of the group, however they did not break with migrants' cooperation networks, which are based on a feeling of belonging to the same nationality. In other words, there is a criticism of the homogenization of the group, but not of the very concept of belonging to a nationality. The following example expressed by a young Venezuelan dedicated to commerce is illustrative of what was expressed:

Well, in the time that I migrated, the Ecuadorian people were kinder, kind and respectful towards us Venezuelans, but now because of the things and the violence that has arisen 
in Ibarra and throughout Ecuador, the Venezuelan people no longer love us and we They are branded as violent, but in reality it is not like that, many of us are humble and we come in peace (Santiago, Personal Interview, June 2019).

Months after the Diana Case, the Ecuadorian government decided to create a mandatory visa requirement for all Venezuelan citizens. In conversations with several of our informants, it was shown that this measure was not completely badly received by many members of the Venezuelan migrant community. Many people stated that generating more controls on the type of people who enter Ecuador is positive for the image of the migrants settled in the city. This position is exemplified in comments such as the following expressed by Juan, a worker in electronics sales:

I agree (with the measures adopted by the government), now for Venezuelans it is also a problem that criminals are here for us, it is a problem that Venezuelans are there smoking drugs in Pedro Moncayo Park, it is a problem not only for Ecuadorians The problem is also for the Venezuelans who are here working every day, earning a living, specifically. Because stigmatization includes everyone, they are going to put us all in that bag, so if the government can do something to control that, much better, and not only should the central government be there, there should also be local governments (Juan, Interview Staff, November 2019).

These discourses constitute a critique of homogenization, including migration policies. This is developed in a strategic way because although they emphasized differences, the feeling of belonging to the Venezuelan nationality is not questioned. Similar processes have been discussed by Lacy (2007) in relation to the assimilation of Afro-descendant people into uppermiddle-class white communities in the United States. According to this author, despite the assimilation processes of this group, people maintained selective and strategic contacts with members of their own ethnic group. In the case of Venezuelan migration, identification based on nationality also allows for the maintenance of certain cooperation networks.

The literature has frequently studied the characteristics of contemporary migration through the lens of migratory networks, highlighting its importance in meeting the basic needs of migrants and facilitating the arrival of new members (Deker and Engbersen, 2014; Light, Bhachu and Karageorgis 2014; Stuart and Tylor, 2018). According to Arango (2017), migratory networks "transmit information, provide financial assistance, facilitate employment and accommodation, and provide support in multiple ways. By doing so, they reduce the costs and uncertainty of migration, and therefore facilitate it". In this sense, migratory networks are forms of social and cultural capital (Bourdieu 1999) that facilitate the living conditions of migrants and explain the formation of communities in certain geographical areas.

The city of Ibarra has certain cooperation networks between migrants, mainly focused on commercial and informal work, and on the exchange of information on living conditions, contacts, accommodation and job opportunities. In the case of the Venezuelan migration, these networks are based on their nationality. These forms of cooperation are developed both through face-to-face and in virtual spaces (internet). On digital platforms, sites such as Facebook have groups for Venezuelan migrants in Ibarra, in certain with more than 15,000 members. These platforms become a space to generate contacts with other members of the community, or to strengthen ties established through face to face contact. The information that flows on these platforms is valuable to function within the city or to maintain transnational links with the country of origin. For example, information on how to send remittances or medicines from Ibarra to Venezuela, accommodation or employment, or guides on bureaucratic processes. These networks are made up of people from different spaces, genders and social conditions. In 
practice, these networks are maintained through a constant exchange that goes from virtual to face-to-face, and vice versa.

For example, for Moisés, a young man currently engaged in informal commerce, these networks of friends facilitated his arrival to Ibarra. Although at first his interest was not to settle permanently in Ibarra, this network of contacts influenced his decision to settle in the city: "I did not have family here in Ibarra, but I did have friends who arrived before me (...) at first I did not know anything, my objective was not to stay in this city, I only came to experiment and find something better". Belonging to these networks made it easier for him to find accommodation and develop his trade in commerce.

Through virtual spaces, access to these networks becomes extremely easy, since generally there are no filters that prevent the entry of new members. The basis of these networks is the feeling of belonging to the Venezuelan nationality. Nationality in this sense can be understood as an imagined community (Anderson 2006), which allows maintaining important ties even within transnational migration. After the events of the Diana Case, these networks have been maintained and strengthened with the arrival of new migrants. All this is developed in parallel with the narratives that try to criticize the homogenization of the Venezuelan community.

In this sense, several of the responses to xenophobia regarding the Diana case can be understood through the theoretical lens of strategic construction of identity. On the one hand, people generate discourses that emphasize heterogeneity, and on the other, they maintain cooperation networks based on belonging to a nationality. The discursive elements show the interest in breaking with homogenizing visions about migration, which are related to the generation of hate and xenophobia. All of this does not prevent the development of transversal cooperation networks.

Authors such as Papastergiradis (2018) have demonstrated the analytical problems of understanding identity in migration contexts in terms of essential identities, since these visions are based on basic opposition, which obstruct the analysis of the diversity and complexity existing within each of these groups. In this sense, categories such as "ethnic" (Wallendorf and Reilly 1983), commonly used in the literature on migration, are not adequate to understand this population, because they theoretically homogenize diverse groups. In this article it has been seen how, in the face of the complex panorama posed by xenophobia, the migrants settled in the city of Ibarra strategically emphasize the heterogeneity of the group, while maintaining collaborative relationships

\section{Conclusions}

Migration is a complex and constantly changing phenomenon. The interrelationships between locals and migrants in cities like Ibarra are not straightforward. The events of the Diana case presented in the article constitute a form of externalization of xenophobic attitudes. In such contexts, the construction of migratory identities is developed in a strategic way. On the one hand, a critique of the homogenizing rationality of xenophobic discourses is developed, whereby migrants emphasize the heterogeneity of their community. On the other hand, collaboration networks based on belonging to a nationality are maintained either through faceto-face or virtual spaces, since these networks constitute an important input for migratory life. The current crisis in Venezuela has led to one of the largest migratory movements in South American history. This migratory phenomenon has had implications even within spaces that were traditionally outside the dynamics of mass migration, including border cities such as Ibarra. For these cities, this type of migration generally constitutes an unexpected phenomenon, for which there was no planning. The symbolic dynamics and the interaction between groups within these spaces are complex and deserve to be studied in depth from anthropology. The 
analysis on discourses of heterogeneity, cooperation networks and xenophobia presented in this article seeks to contribute precisely to strengthening this field of studies.

\section{References}

Arango, J. (2017). Theories of international migration. In International migration in the new millennium, ed. Daniele Joly, 25-45. Abingdon: Routledge.

Anderson, B. (2006). Imagined Communities Reflections on the Origin and Spread of Nationalism. Routledge.

Archakis, A. (2018). The Representations of Racism in Immigrant Students' Essays in Greece: The 'Hybrid Balance' between Legitimizing and Resistance Identities. Pragmatics. https://doi.org/10.1075/prag.16016.arc

Arrocha, W. (2019). Combating Xenophobia and Hate through Compassionate Migration: The Present Struggle of Irregular Migrants Escaping Fear and Extreme Poverty. Crime, Law and Social Change 71 (3): 245-60. https://doi.org/10.1007/s10611-019-09833-w

Barth, F. (1998). Ethnic Groups and Boundaries: The Social Organization of Culture Difference. Boston: Little, Brown

Beuving, J \& De Vries, G. (2015). Doing qualitative research: The craft of naturalistic inquiry. Amsterdam: Amsterdam University Press.

Botia, A. (2019). The Venezuelan Diaspora: Toward a New Understanding of Forced Migration. Tesis doctoral, Vanderbilt University.

Borneman, J. (1986). Emigres as Bullets/Immigration as Penetration Perceptions of the Marielitos. The Journal of Popular Culture. https://doi.org/10.1111/j.00223840.1986.2003_73.x.

Bourdieu, P. (1999). Las formas de capital. Lima: Editorial Piedra Azul.

Bursztyn, L., Egorov, G., Enikolopov, R. \& Petrova, M. (2019). Social media and xenophobia: evidence from Russia. Nber Working Paper: 1.27.

Cervone, E., \& Rivera, F. (1999). Ecuador Racista Imágenes e Identidades. Flacso, Ecuador

Conversi, D. (2009). Cultural Homogenization, Ethnic Cleansing, and Genocide. The International Studies Encyclopedia. https://doi.org/10.13140/RG.2.1.2623.5603

Crush, J. \& Ramachandran, S. (2010). Xenophobia, International Migration and Development. Journal of Human Development and Capabilities. 11 (2): 209-28. https://doi.org/10.1080/19452821003677327

Dekker, R. \& Engbersen, J. (2014). How social media transform migrant networks and facilitate migration. Global Networks. 14, no. 4: 401-418.

Dunn, K., Klocker, N. \& Salabay, T. (2007). Contemporary Racism and Islamaphobia in Australia: Racializing Religion. Ethnicities. https://doi.org/10.1177/1468796807084017.

Frías-Vázquez, M., \& Arcila, C. (2019). Hate Speech against Central American Immigrants in Mexico: Analysis of Xenophobia and Racism in Politicians, Media and Citizens. In ACM International Conference Proceeding Series. https://doi.org/10.1145/3362789.3362850.

Haegel, F. (2000). Xenophobia on a suburban Paris housing estate. Patterns of prejudice 34, no. 1: 29-38. 
Harris, S., Findley, D., \& Noyes, K. (2018). The Economic Roots of Anti-Immigrant Prejudice in the Global South: Evidence from South Africa. Political Research Quarterly. https://doi.org/10.1177/1065912917734062.

Herrera, G., \& Torres, A. (2005). La migración ecuatoriana: transnacionalismo, redes e identidades. Quito: Flacso.

Hjerm, M, \& Nagayoshi, K. (2011). The Composition of the Minority Population as a Threat: Can Real Economic and Cultural Threats Explain Xenophobia? The Evolution of Prejudice View Project Research on Social and Institutional Factors Affecting Anti-Immigrant Attitudes in Japan View Project. International Sociology. 26 (6): 815-43. https://doi.org/10.1177/0268580910394004.

INEC. 2010. Censo de Población y vivienda. Quito: INEC.

Karam, R. (2020). Becoming American by Becoming Muslim: Strategic Assimilation among Second-Generation Muslim American Parents. Ethnic and Racial Studies. https://doi.org/10.1080/01419870.2019.1578396.

Kirksey, E, y Helmreich, S. (2010). The Emergence of Multispecies Ethnography. Cultural Anthropology. https://doi.org/10.1111/j.1548-1360.2010.01069.x.

Kraly, E., \& Hovy, B. (2020). Data and Research to Inform Global Policy: The Global Compact for Safe, Orderly and Regular Migration. Comparative Migration Studies. https://doi.org/10.1186/s40878-019-0166-y.

Lacy, K. (2007). Blue-Chip Black: Race, Class, and Status in the New Black Middle Class. Contemporary Sociology: A Journal of Reviews https://doi.org/10.1177/009430610803700411.

Landmann, H., Gaschler, R. \& Rohmann, A. (2019). What Is Threatening about Refugees? Identifying Different Types of Threat and Their Association with Emotional Responses and Attitudes towards Refugee Migration. European Journal of Social Psychology. 49 (7): 140120. https://doi.org/10.1002/ejsp.2593.

Leónova, O. (2019). Problemas de migración y litigios territoriales crisis migratoria en latinoamérica. Iberoamerica 3.

Light, I., Bhachu, P. y Karageorgis, P. (2017). "Migration networks and immigrant entrepreneurship". En Immigration and entrepreneurship, editado por Parminder Bhachu, 25-50. Abingdon: Routledge.

Martínez, L, Ortega, P., Martínez, M. \& Rengifo, M. (2019). Discursos de odio: una epidemia que se propaga en la red. Estado de la cuestión sobre el racismo y la xenofobia en las redes sociales. Mediaciones Sociales 18: 25-43.

Martínez Novo, C. (2018). Ventriloquism, Racism and the Politics of Decoloniality in Ecuador. Cultural Studies. https://doi.org/10.1080/09502386.2017.1420091.

McLaren, L. (2002). Public Support for the European Union: Cost/Benefit Analysis or Perceived Cultural Threat? Journal of Politics. 64 (2): 551-66. https://doi.org/10.1111/14682508.00139.

Meijl, T. (2008). Culture and Identity in Anthropology: Reflections on 'unity' and 'Uncertainty' in the Dialogical Self. International Journal for Dialogical Science. 3 (1): 16590.

OIM. 2020. Monitoreo de flujo de población venezolana. Ecuador. Quito: OIM. 
Palotti, J., Adler, N., Morales-Guzman, A., Villaveces, J., Sekara, V.,

Pantoulas, D., \& McCoy, J. (2019). Venezuela: An Unstable Equilibrium. Revista de Ciencia Politica. https://doi.org/10.4067/S0718-090X2019000200391.

Papastergiadis, N. (2018). The turbulence of migration: Globalization, deterritorialization and hybridity. Hoboken: John Wiley \& Sons.

Pardo, I., y Giuliana, P. (2018). The Palgrave handbook of urban ethnography. New York: Palgrave Macmillan.

Radcliffe, S. (2015). Dilemmas of Difference: Indigenous Women and the Limits of Postcolonial Development Policy. Durham: Duke University Press.

Van Ramshorst, J. (2020). Studying Migration in the Time of Trump: Power, Positionality, and Formal Politics in the Field. Professional Geographer. https://doi.org/10.1080/00330124.2019.1662819.

Rodríguez Cruz, M. (2018). Construir La Interculturalidad. Políticas Educativas, Diversidad Cultural y Desigualdad En El Ecuador. Íconos - Revista de Ciencias Sociales. https://doi.org/10.17141/iconos.60.2018.2922.

Roitman, K, and Oviedo, A. (2017). Mestizo Racism in Ecuador. Ethnic and Racial Studies. https://doi.org/10.1080/01419870.2016.1260749.

Schlueter, E, \& Scheepers, P. (2010). The Relationship between Outgroup Size and AntiOutgroup Attitudes: A Theoretical Synthesis and Empirical Test of Group Threat- and Intergroup Contact Theory. Social Science Research. https://doi.org/10.1016/j.ssresearch.2009.07.006.

Stuart, B., y Taylor, E. (2018). Migration Networks and Location Decisions: Evidence from US Mass Migration. IZA Discussion Paper, n. 12709.

Tafira, K. (2011). Is Xenophobia Racism?. Anthropology Southern Africa. https://doi.org/10.1080/23323256.2011.11500015.

Wallendorf, M., \& Reilly, M. (1983). Ethnic migration, assimilation, and consumption. Journal of Consumer Research 10, no. 3: 292-302.

Wilson, T. (2001). Reflexive Ethnography: A Guide to Researching Selves and Others:Reflexive Ethnography: A Guide to Researching Selves and Others. American Anthropologist. https://doi.org/10.1525/aa.2001.103.2.566.

Wimmer, A., \& Glick Schiller, N. (2003). "Methodological Nationalism, the Social Sciences, and the Study of Migration: An Essay in Historical Epistemology". International Migration Review 37 (3): 576-610. https://doi.org/10.1111/j.1747-7379.2003.tb00151.x. 